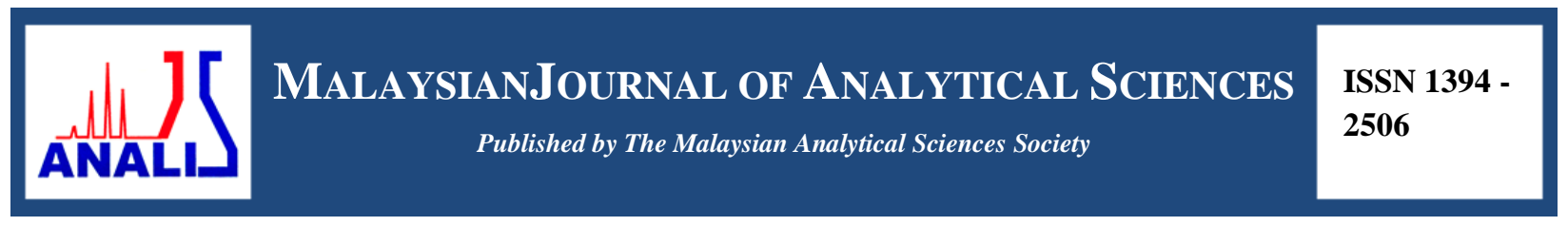

\title{
KAJIAN KELIKATAN PELARUT EUTEKTIK RELINA TERHADAP PENGEKSTRAKAN $\alpha$-TOKOFEROL DARIPADA MINYAK SAWIT MENTAH
}

\author{
(Study on Viscosity of Reline Deep Eutectic Solvent on The $\alpha$-Tocopherol Extraction From \\ Crude Palm Oil)
}

\author{
Noor Hasyimah Hussain, Zetty Shafiqa Othman, Edison Eukun Sage, Rozida Mohd Khalid, \\ Nur Hasyareeda Hassan* \\ Pusat Pengajian Sains Kimia dan Teknologi Makanan, \\ Fakulti Sains dan Teknologi, \\ Universiti Kebangsaan Malaysia, 43600 UKM Bangi, Selangor, Malaysia \\ *Pengarang utama: syareeda@ukm.edu.my
}

Received: 7 June 2017; Accepted: 14 March 2018

\begin{abstract}
Abstrak
DES Relina diklasifikasikan sebagai pelarut hijau dan serasi untuk digunakan bagi pengekstrakan $\alpha$-tokoferol ( $\alpha$-T) daripada minyak sawit mentah (CPO) kerana kemampuannya untuk membentuk ikatan hidrogen yang kuat dengan molekul $\alpha$-T. Kepekatan dan hasil $\alpha-T$ dikuantifikasi menggunakan kromatografi cecair prestasi tinggi fasa berbalik (RP-HPLC). Dua parameter dikaji melalui penggunaan lima siri nisbah CPO: DES relina (1: 1, 1:2, 1: 3, 1: 4 dan 1: 5) pada 2 dan 3 jam masa pengekstrakan untuk mengenalpasti keadaan optimum bagi pengekstrakan $\alpha$-T. Kepekatan $\alpha$-T untuk semua sampel yang diekstrak dibandingkan dengan kawalan (tanpa DES relina) memberikan nisbah 1: 2 (CPO: DES relina) dengan kelikatan pelarut $5.7 \pm 0.58 \mathrm{cP}$ pada 3 jam masa pengekstrakan sebagai keadaan pengekstrakan terbaik bagi mendapatkan kepekatan $\alpha-\mathrm{T}$ tertinggi iaitu $825.321 \pm 74.27 \mathrm{mg} / \mathrm{L}$ dengan keberhasilan $0.1554 \pm 0.0156(\%)$. Perkara ini menunjukkan bahawa keadaan tersebut merupakan keadaan yang paling kondusif bagi penyerapan molekul $\alpha$-T ke dalam ruang kosong dalam struktur pelarut di mana molekul $\alpha$-T dan DES relina berinteraksi melalui ikatan hidrogen. Ikatan hidrogen yang kuat terbentuk antara kumpulan $-\mathrm{OH} \alpha-$ $\mathrm{T}$ dengan kumpulan amina $-\mathrm{NH}_{2}$ DES relina merupakan faktor peningkatan keupayaan DES relina untuk mengekstrak sebatian $\alpha$-T yang tinggi daripada $\mathrm{CPO}$.
\end{abstract}

Kata kunci: penderma ikatan hidrogen, pelarut eutektik dalam relina, tokoferol, kelikatan

\begin{abstract}
Reline DES was classified as a green solvent and compatible to be used for $\alpha$-tocopherol ( $\alpha$-T) extraction from crude palm oil (CPO) due to its ability to form strong hydrogen bond with $\alpha$-T molecule. The $\alpha$-T concentration and yield was quantified using reverse phase high performance liquid chromatography (RP-HPLC). Two parameters were studied through utilization of five CPO: Reline DES ratio series (1:1, 1:2, 1:3, 1:4 and 1:5) at 2 and 3 hours extraction time in determining optimize $\alpha$-T extraction condition. Concentration of $\alpha$-T for all extracted samples was compared to the control (without reline DES) resulted towards CPO: Reline DES ratio of 1:2 with solvent viscosity of $5.7 \pm 0.58 \mathrm{cP}$ at 3 hours extraction time as the best condition to obtain the highest $\alpha$-T concentration of $825.321 \pm 74.27 \mathrm{mg} / \mathrm{L}$ with the yield of $0.1554 \pm 0.0156(\%)$. It can be concluded that this condition is the most conducive for $\alpha$-T molecules diffusion into free space of solvent structure in which molecules of $\alpha$-T and reline DES interact through hydrogen bond. The strong hydrogen bond formed between $-\mathrm{OH}$ group of $\alpha-\mathrm{T}$ and $-\mathrm{NH}_{2}$ group of reline DES is the factor enhancing the capability of reline DES to extract higher $\alpha$-T compound from CPO.
\end{abstract}

Keywords: hydrogen bond donor, reline deep eutectic solvent, tocopherol, viscosity 


\section{Pengenalan}

Sebatian $\alpha$-tokoferol (Rajah 1(a)) merupakan salah satu terbitan vitamin E yang berupaya bertindak sebagai agen anti pengoksidaan dalam merawat penyakit kanser. Selain itu, sebatian vitamin E juga dikatakan sebagai terapi yang berpotensi merawat penyakit neurodegenaratif seperti Alzheimer dan Sindrom down [1]. Sebatian alfa tokoferol sering digunakan dalam bidang penyelidikan dan bidang perubatan. Kepentingan sebatian ini dalam pelbagai bidang menjadikan sebatian tokoferol mendapat permintaan yang tinggi [2]. Sebatian tokoferol boleh diperoleh daripada sumber asli seperti minyak sawit mentah (CPO) dan minyak ini mengandungi lima jenis isomer vitamin E iaitu $\alpha$ tokoferol $\left(\alpha\right.$-T), $\alpha$-tokotrienol $\left(\alpha-T_{3}\right), \gamma$-tokoferol $\left(\gamma\right.$-T), $\gamma$-tokotrienol $\left(\gamma-T_{3}\right)$ dan $\delta$-tokotrienol $\left(\delta-T_{3}\right)$ [3-6].

Pada tahun 2011, Goossens dan Marion [7] telah menjalankan kajian mengenai pengekstrakan sebatian $\alpha$ - dan $\delta$ - T daripada minyak Canola dan minyak kacang soya melalui kaedah emparan dan pusaran pada kelajuan $3000 \mathrm{rpm}$ selama lima minit. Walaubagaimanapun, menurut Goossens dan Marion [7], kaedah pengekstrakan yang digunakan adalah tidak sempurna kerana menyebabkan degradasi sebatian tokoferol. Penyimpanan sebatian yang tidak mengikut keadaan yang sesuai juga $\left(-20^{\circ} \mathrm{C}\right)$ merupakan faktor sebatian ini teroksida dan terdegradasi. Oleh yang demikian, kajian yang melibatkan sebatian seperti tokoferol memerlukan pengendalian yang teliti bagi mengurangkan degradasi sebatian ini memandangkan sifatnya yang sensitif terhadap, haba, cahaya dan udara [8].

Sebatian vitamin $\mathrm{E}$ juga boleh diperoleh melalui kaedah pengekstrakan dengan menggunakan pelarut organik sebagai medium pengekstrakan. Kajian sebelum ini oleh Sanagi et al. [9] menggunakan pelarut organik heksana dalam kaedah pengekstrakan cecair bertekanan (PLE) memberikan pengekstrakan kandungan vitamin $\mathrm{E}$ yang tinggi. Walaubagaimanapun, penggunaan pelarut organik heksana pada suhu dan tekanan yang tinggi adalah berbahaya kerana pelarut ini mudah terbakar [10]. Secara konvensional pelarut organik sering digunakan bagi pengekstrakan sebatian $\alpha$-T daripada sumber semula jadi. Namun, penggunaan pelarut organik menghasilkan kepekatan dan keberhasilan pengekstrakan yang rendah selain sifatnya yang toksik dan mudah meruap adalah berbahaya kepada pengguna.

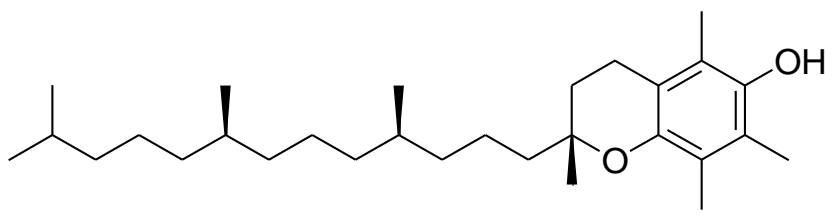

(a)<smiles>C[N+](C)(Cl)CCO</smiles>

(b)

Rajah 1. (a) Struktur kimia $\alpha$-tokoferol (B) DES relina

Oleh yang demikian, pelarut hijau seperti pelarut eutektik dalam (DES) semakin giat dikaji oleh penyelidik masa kini dalam pelbagai bidang penyelidikan. Hal ini kerana ia merupakan pelarut yang mesra alam, murah dan tidak bertoksik [11]. Di samping itu, ciri-ciri pensolvatan yang luar biasa oleh pelarut hijau DES [12] menjadikan pelarut ini sesuai digunakan sebagai pelarut hijau alternatif dalam pengekstrakan sebatian $\alpha$-T. DES merupakan campuran dua atau tiga komponen yang murah dan selamat di mana kesemua komponen ini berupaya untuk bercampur antara satu sama lain melalui pembentukan ikatan hidrogen sehingga menghasilkan campuran eutektik [13]. Secara umumnya, DES terdiri daripada kombinasi garam pepejal dan kumpulan penderma ikatan hidrogen pada perkadaran yang berbeza. 
DES mempunyai ciri-ciri yang sama seperti cecair ionik bahkan ia mempunyai beberapa kelebihan lain [14] seperti proses penyediaan yang mudah dalam keadaan tulen, tidak reaktif terhadap air dan sebahagiannya bersifat biodegradasi. Selain itu, DES merupakan pelarut hijau yang larut dalam air, tidak mudah terbakar dan tidak mudah meruap. Ciri-ciri ini menjadikan DES berpotensi sebagai pelarut yang efektif untuk proses pelarutan sempurna dan pelarut pengekstrakan sebatian berkutub dan tidak berkutub. Nu'man et al. [15] telah mengkaji penggunaan DES terbitan tiga jenis asid karboksilik sebagai pelarut pengekstrakan sebatian vitamin E melalui kaedah pengekstrakan cecair-cecair (LLE). Penggunaan DES menunjukkan kecekapan pengekstrakan yang lebih baik berbanding pelarut organik konvensional. Tambahan pelarut ini juga boleh di kitar dan diguna semula dalam proses pengekstrakan.

Dalam kajian ini, DES relina digunakan sebagai pelarut pengekstrakan sebatian $\alpha$-T. Rajah 1 (a) dan 1(b) menunjukkan struktur $\alpha$-T dan DES relina. DES relina merupakan pelarut homogen yang terdiri daripada campuran garam ammonium kuarterner (kolin klorida, $\mathrm{ChCl}$ ) dan penderma ikatan hidrogen (urea) yang dihasilkan pada nisbah 1:2 dengan pengacauan dan pemanasan pada suhu $85^{\circ} \mathrm{C}$.

Walaubagaimanapun, kelikatan DES relina yang tinggi merupakan halangan untuk sebatian $\alpha$-T berinteraksi dengan molekul pelarut ini. Oleh itu, kajian ini dijalankan bagi menentukan keadaan pengekstrakan terbaik bagi mengekstrak sebatian $\alpha$-T secara optimum dengan mengkaji kesan kelikatan DES relina pada lima nisbah DES relina yang berbeza dengan masa pengekstrakan (2 dan 3 jam) terhadap kepekatan ekstrak sebatian $\alpha$-T.

\section{Bahan kimia}

\section{Bahan dan Kaedah}

Minyak sawit mentah diperoleh daripada Sime Darby Berhad Malaysia manakala bahan kimia yang digunakan dalam kajian ini merupakan kolin klorida, asetonitril gred HPLC dan gred analisis, heksana, metanol, urea dan piawai $\alpha$-T (95.5\%). Kesemua bahan kimia diperoleh daripada R\&M kecuali piawai $\alpha$-Tyang diperoleh daripada Sigma Aldrich.

\section{Penyediaan DES relina}

DES relina disediakan dengan mencampurkan kolin klorida $(\mathrm{ChCl})$ dan urea pada nisbah molar 1:2. Campuran ini dipanaskan pada suhu $85{ }^{\circ} \mathrm{C}$ sambil dikacau menggunakan pengacau magnet sehingga larutan menjadi homogen dan tidak berwarna terbentuk [16].

\section{Pengekstrakan $\alpha$-Tokoferol}

Bagi nisbah 1:1 CPO kepada DES relina, 10 g CPO dilarutkan dalam $100 \mathrm{~mL}$ heksana manakala $10 \mathrm{~g}$ DES dilarutkan dalam $100 \mathrm{~mL}$ metanol. Kedua-dua bahan ini dicampurkan dalam kelalang kon $250 \mathrm{~mL}$ yang dibalut dengan kerajang aluminium dan dikacau selama 2 jam. Campuran ini seterusnya dipindahkan ke dalam corong pemisah dan dibiarkan seketika untuk membentuk dua lapisan. Lapisan DES kemudian dicampurkan dengan campuran heksana-air (1:4) sebelum fasa tokol-heksana dipisahkan daripada pelarut DES. Isi padu fasa tokolheksana diukur dan dipindahkan ke dalam vial yang dibalut dengan kerajang aluminium dan produk disimpan pada suhu $-4^{\circ} \mathrm{C}$ sebelum dianalisis menggunakan kromatografi cecair prestasi tinggi fasa berbalik (RP-HPLC). Pengekstrakan diulang dengan menggunakan nisbah CPO kepada DES yang berbeza iaitu 1:2, 1:3, 1:4 dan 1:5. Kelima-lima nisbah ini dikaji pada masa pengekstrakan 2 dan 3 jam. Setiap pengekstrakan yang dilakukan mestilah dalam keadaan terhindar daripada cahaya. Langkah ini penting bagi mengelakkan degradasi sebatian $\alpha$-T kerana sifatnya yang sensitif terhadap cahaya dan udara. Eksperimen bagi kawalan pengekstrakan diulang tanpa penggunaan DES relina.

\section{Analisis struktur DES relina}

Elusidasi dan analisis DES relina dilakukan dengan menggunakan kaedah spektroskopi resonans magnetik nukleus (NMR) dan spektroskopi inframerah transformasi Fourier (FTIR). Sampel urea dan DES relina dilarutkan dengan pelarut dimetilsulfoksida (DMSO) yang terdeuterat- $\mathrm{d}_{6}$ bagi analisis NMR satu dimensi $(1 \mathrm{D}),\left({ }^{1} \mathrm{H}\right.$ dan $\left.{ }^{13} \mathrm{C}\right)$. Selain itu, struktur DES relina juga ditentukan melalui mod dua dimensi (2D) iaitu NOESY dan HMQC. Analisis melalui spektroskopi FTIR adalah melalui mod ATR. Spektrum DES relina daripada kedua-dua kaedah spektroskopi dibandingkan dengan spektrum penderma ikatan hidrogen urea. 


\section{Analisis kelikatan DES relina}

DES relina $10 \mathrm{~g}, 20 \mathrm{~g}, 30 \mathrm{~g}, 40 \mathrm{~g}$ dan $50 \mathrm{~g}$ mengikut nisbah 1,2,3,4 dan 5 masing-masing disediakan di dalam bikar. Kelima-lima sampel pelarut ini masing-masing dilarutkan ke dalam $100 \mathrm{~mL}$ metanol. Kemudian, kelikatan kelimalima sampel larutan ini dikaji menggunakan viskometer (spindel bernombor 3 selama 1 minit dengan kelajuan 100 rpm). Kelikatan setiap sampel dicatat dalam unit cP dan setiap kelikatan sampel diukur sebanyak 3 kali.

\section{Analisis kandungan $\alpha-T$}

Sistem HPLC Agilent yang terdiri daripada autosampel dan pisahan $\mathrm{C}_{18}$ Waters berdiameter $4.6 \mu \mathrm{m}$ dengan panjang $250 \mathrm{~mm}$. Pengesan UV digunakan pada panjang gelombang $292 \mathrm{~nm}$ bagi mengesan pemisahan sampel. Asetonitril: air digunakan dalam sistem ini sebagai fasa bergerak pada nisbah 95:5 dengan kadar alir 1.0 mLmin ${ }^{-1}$ pada suhu bilik $\left(30^{\circ} \mathrm{C}\right)$. Graf kalibrasi sebatian $\alpha$-T diplotkan menggunakan lima siri larutan piawai $\alpha-\mathrm{T}(2.5,10,30,40$ dan $80 \mathrm{ppm}$ ). Kepekatan sebatian $\alpha$-T dihitung melalui persamaan (1) dan (2) yang dilaporkan oleh Nu'man et al. [15] manakala bagi peratus hasil ekstrak (\%) dihitung melalui persamaan (3).

$$
C_{i}=1 / G \times A_{i} \times D_{i}
$$

di mana, $C_{i}=$ kepekatan tokoferol $(\mathrm{mg} / \mathrm{L}), \mathrm{G}=$ faktor gerak balas daripada regrasi plot linear, $\mathrm{A}_{\mathrm{i}}=$ keluasan sampel, $\mathrm{D}_{\mathrm{i}}=$ faktor pencairan, ditakrifkan sebagai berat sampel per isi padu pencairan.

$$
\mathrm{D}_{\mathrm{i}}=\mathrm{v}_{\mathrm{i}} / \mathrm{v}_{\mathrm{f}}
$$

di mana, $\mathrm{v}_{\mathrm{i}}=$ isi padu sampel $(\mathrm{mL}), \mathrm{v}_{\mathrm{f}}=$ isipadu sampel esktrak $(\mathrm{mL})$

$$
\text { Peratus hasil ekstrak }(\%)=\frac{\left[\text { Kepekatan tokoferol } \mathrm{C}_{\mathrm{i}} \times \mathrm{Isi} \text { padu akhir ekstrak }(\mathrm{L})\right]}{10000 \mathrm{mg}} \times 100 \%
$$

\section{Ikatan hidrogen dalam Struktur DES relina}

\section{Hasil dan Perbincangan}

DES relina yang disediakan dalam kajian ini menunjukkan bahawa terdapat interaksi antara kolin klorida $(\mathrm{ChCl})$ dan urea melalui ikatan hidrogen. Daripada spektrum perbandingan FTIR (Rajah 2), tiga jalur serapan -NH dalam spektrum urea lebih tajam berbanding dua jalur serapan -NH dalam sampel DES relina. Menurut Pavia et al. [17], amina primer - NH dalam keadaan pepejal menghasilkan jalur getaran yang kuat disebabkan oleh perubahan fasa pepejal urea kepada fasa cecair DES relina. Spektrum FTIR DES relina menunjukkan jalur serapan yang lebih lebar kerana jalur serapan $-\mathrm{OH}$ dalam struktur ion kolin, $\mathrm{Ch}^{+}$bertindih dengan puncak serapan $-\mathrm{NH}_{2}$. Pertindihan ini disebabkan oleh kumpulan -OH dan -NH berada pada julat nombor gelombang yang sama iaitu sekitar $2500 \mathrm{~cm}^{-1}$ hingga $4000 \mathrm{~cm}^{-1}$ [17]. Selain itu, kewujudan ikatan hidrogen antara ion klorida $\mathrm{Cl}^{-}$dan $-\mathrm{NH}_{2}$ dalam struktur DES relina seperti Rajah 3 menyebabkan jalur serapan teranjak kepada julat nombor gelombang yang lebih kecil [18]. Kewujudan ikatan ini disokong kajian oleh Zaira [19] yang menyatakan bahawa pembinaan ikatan hidrogen antara dua komponen ini adalah melalui proton amina sekunder dengan anion $\mathrm{Cl}^{-}$. Kesemua jalur serapan yang ditunjukkan oleh spektrum FTIR urea wujud dalam spektrum FTIR DES relina. Namun, bentuk dan intensiti jalur serapan yang ditunjukkan bagi kedua-dua spektrum adalah berbeza. Perbezaan ini menunjukkan berlakunya interaksi melalui percampuran kolin klorida dan urea bagi penghasilan DES relina. 


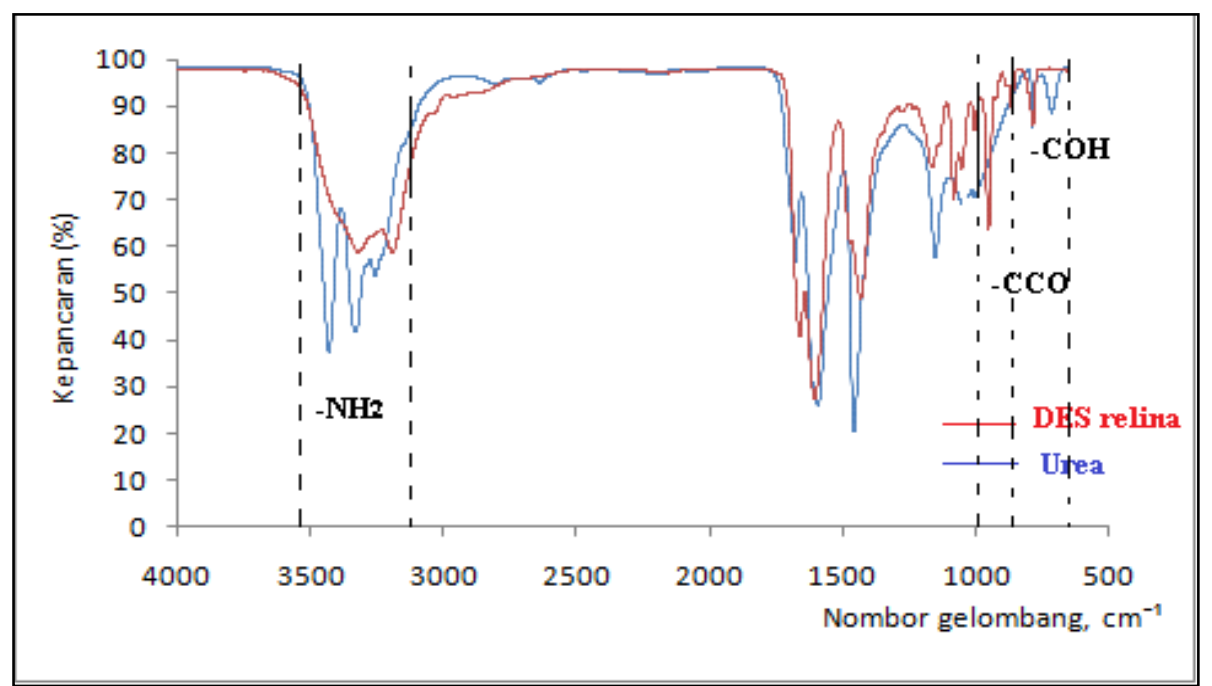

Rajah 2. Perbandingan spektrum FTIR-ATR antara urea dan DES relina<smiles>C[N+](C)(C)CCO</smiles>

Rajah 3. Ikatan hidrogen yang terbentuk dalam struktur DES relina

Struktur DES relina juga disokong melalui spektrum ${ }^{1}$ H-NMR (Rajah 4(b)) di mana terdapat lapan proton sekitar anjakan kimia 3.15 ppm sehingga $5.81 \mathrm{ppm}$ yang mewakili proton urea dan kolin klorida. Anjakan kimia pada 5.81 ppm (Rajah 4 (a)) mewakili proton amina bagi dua molekul urea dan selebihnya mewakili proton kolin klorida. Selain itu, DES relina yang dihasilkan dalam kajian ini juga menunjukkan spektrum DES relina yang sama seperti kajian yang dilakukan oleh Lobo dan Rennet [20]. Tambahan, kelebaran bentuk puncak spektrum ${ }^{1} \mathrm{H}-\mathrm{NMR}$ bagi sampel DES relina ini sama seperti kajian yang dilakukan oleh D'Agostino et al. [21] dan kelebaran puncak proton ini adalah disebabkan oleh kelikatan DES relina yang tinggi [21]. Rajah 5 menunjukkan ${ }^{13} \mathrm{C}-\mathrm{NMR}$ DES relina dan didapati empat karbon sekitar anjakan 53 ppm sehingga $161 \mathrm{ppm}$, dimana anjakan kimia pada $161 \mathrm{ppm}$ mewakili karbon pada urea dan anjakan kimia selebihnya (53.58 ppm, $55.52 \mathrm{ppm}, 67.31 \mathrm{ppm}$ ) mewakili karbon dalam kolin klorida. 
Noor Hasyimah et al: STUDY ON VISCOSITY OF RELINE DEEP EUTECTIC SOLVENT ON THE $A$-TOCOPHEROL EXTRACTION FROM CRUDE PALM OIL

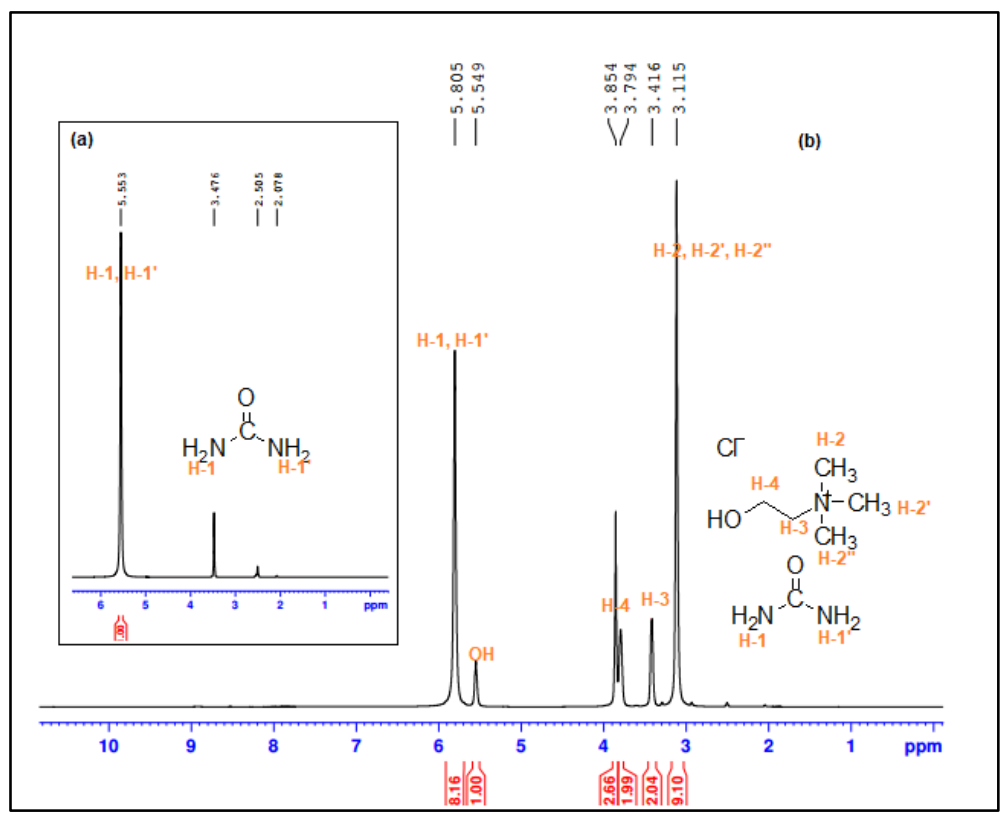

Rajah 4. Spektrum ${ }^{1}$ H-NMR (a) urea dan (b) DES relina

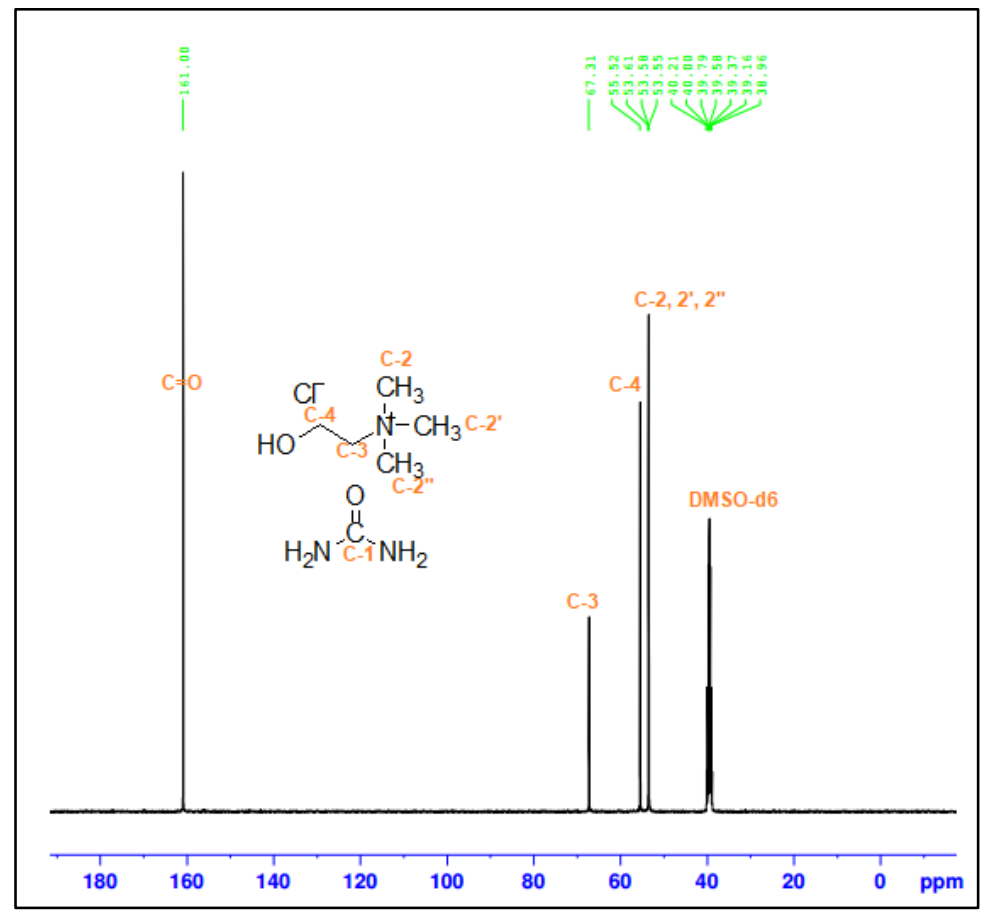

Rajah 5. Spektrum ${ }^{13}$ C-NMR DES relina

Daripada perbandingan spektrum FTIR-ATR, ${ }^{1} \mathrm{H}-\mathrm{NMR}$ dan ${ }^{13} \mathrm{C}-\mathrm{NMR}$ urea dan DES relina, didapati bahawa tiada kemusnahan bagi struktur urea. Analisis 2D HMQC juga menunjukkan interaksi langsung antara proton dan karbon yang terdapat pada struktur DES relina (Rajah 6). Berdasarkan spektrum NMR 2D, interaksi atom karbon dan hidrogen pada struktur ion kolin, $\mathrm{Ch}^{+}$menunjukkan molekul ini tidak musnah semasa proses penghasilan DES 
relina [22]. Selain itu, spektrum yang ditunjukkan menepati struktur DES relina di mana hanya terdapat interaksi langsung antara atom karbon dan hidrogen bagi ion $\mathrm{Ch}^{+}$manakala bagi molekul penderma ikatan hidrogen urea tiada interaksi yang ditunjukkan kerana atom karbon tidak terikat kepada hidrogen secara langsung (C1 dan $\mathrm{H} 1)$.

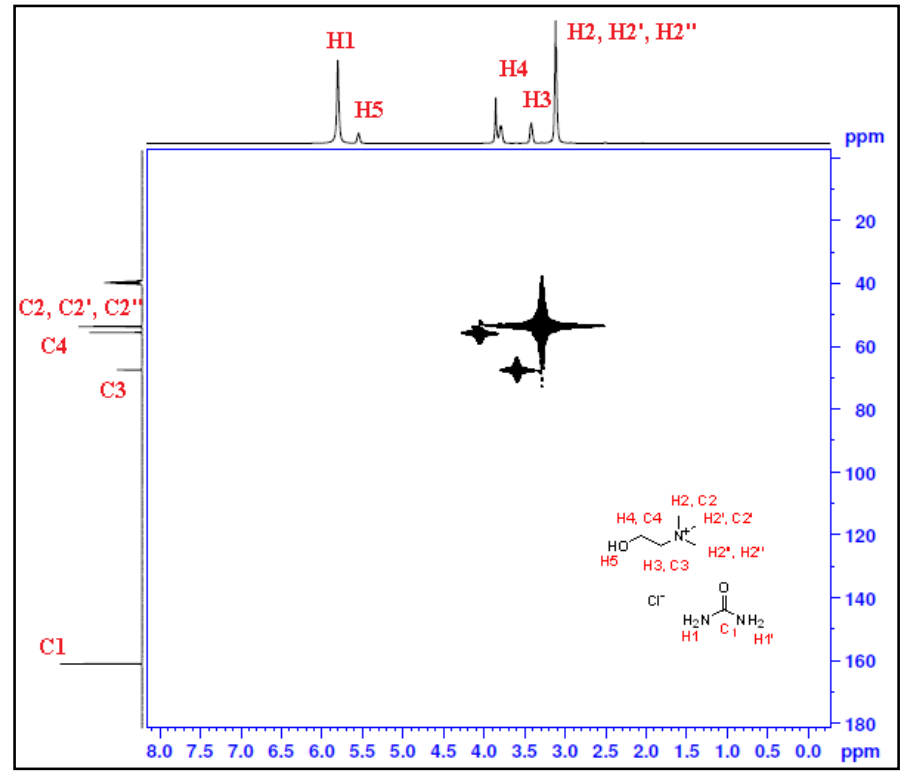

Rajah 6. Spektrum HMQC bagi DES relina

\section{Kesan kelikatan DES relina ke atas pengekstrakan $\alpha$-Tokoferol}

Pengekstrakan cecair-cecair (LLE) memerlukan pembentukan dua fasa bagi membolehkan pemisahan berlaku. DES relina merupakan sebatian hidrofilik kerana ciri pensolvatan yang baik dengan pelarut air. Salah satu ciri pelarut yang digunakan dalam pengekstrakan bagi penghasilan produk yang optimum adalah kelikatan [23]. Oleh sebab kelikatan DES lebih tinggi berbanding pelarut konvensional organik [24], proses pelarutan DES relina ke dalam pelarut metanol dilakukan sebelum pengekstrakan. Proses pelarutan ini bertujuan bagi mengurangkan kelikatan pelarut dan memperbaiki pekali taburan dalam kedua-dua komponen [25]. Proses ini penting bagi membolehkan molekul $\alpha$-T tersebar ke dalam pelarut DES relina ini.

Menurut Duran et al. [24], kelikatan suatu DES terhasil daripada rangkaian ikatan hidrogen, Van der Waals dan juga interaksi elektrostatik. Kelikatan DES adalah disebabkan oleh kehadiran rangkaian ikatan hidrogen yang tinggi antara komponen DES sehingga mengurangkan pergerakan spesies ion bebas dalam struktur pelarut DES sendiri $[13,26]$. Menurut Zhang et al. [13], saiz ion yang besar dan isi padu bebas yang kecil juga salah merupakan satu faktor peningkatan kelikatan pelarut DES. Oleh itu, penyelidik menggunakan teori kelompangan bagi mengurangkan kelikatan DES melalui penggunaan komponen DES yang mempunyai saiz spesies ion bebas yang lebih kecil bagi meningkat isi padu bebas yang diperlukan untuk spesies ion bebas ini bergerak dalam struktur DES sendiri [27].

Ujian kelikatan bagi setiap nisbah DES relina yang digunakan dalam pengekstrakan dilakukan bagi mengetahui kesan kelikatan DES relina ke atas kepekatan dan peratus hasil ekstrak $\alpha$-T. Kelikatan DES relina yang dihasilkan pada nisbah 1:2 (kolin klorida: urea) adalah $169 \mathrm{cP}$ [27]. Berdasarkan Jadual 1, kelikatan bagi semua nisbah DES yang dikaji menunjukkan bacaan jauh lebih rendah iaitu $<<<169 \mathrm{cP}$. Penurunan bacaan kelikatan DES relina ini disebabkan oleh pelarutan pelarut ini ke dalam $100 \mathrm{~mL}$ metanol. Proses pelarutan DES relina telah meningkatkan isi padu bebas dan meningkatkan pergerakan spesies ion bebas dalam struktur pelarut ini. 
Noor Hasyimah et al: STUDY ON VISCOSITY OF RELINE DEEP EUTECTIC SOLVENT ON THE $A$-TOCOPHEROL EXTRACTION FROM CRUDE PALM OIL

Jadual 1.Kelikatan bagi lima nisbah DES relina yang digunakan dalam pengekstrakan $\alpha-\mathrm{T}$

\begin{tabular}{lcccc}
\hline \multirow{2}{*}{$\begin{array}{l}\text { Nisbah DES } \\
\text { Relina (g) }\end{array}$} & \multicolumn{2}{c}{ Bacaan Kelikatan Viskometer (cP) } & \multirow{2}{*}{$\begin{array}{c}\text { Kelikatan DES Relina } \\
\text { dalam 100 mL Pelarut } \\
\text { Metanol (cP) }\end{array}$} \\
\cline { 2 - 4 } & Replikat $\mathbf{~}$ & Replikat 2 & Replikat 3 & $5.0 \pm 0.00$ \\
\hline 1 & 5.0 & 5.0 & 5.0 & $5.7 \pm 0.58$ \\
2 & 5.0 & 6.0 & 6.0 & $8.3 \pm 0.58$ \\
3 & 8.0 & 8.0 & 9.0 & $10.0 \pm 0.00$ \\
4 & 10.0 & 10.0 & 10.0 & $10.7 \pm 0.58$ \\
5 & 10.0 & 11.0 & 11.0 & \\
\hline
\end{tabular}

Merujuk Jadual 1, kelikatan pelarut semakin meningkat apabila nisbah DES relina ditingkatkan. Hasil kajian kelikatan menunjukkan peningkatan dalam kuantiti DES relina yang dilarutkan ke dalam $100 \mathrm{~mL}$ pelarut metanol menyebabkan semakin banyak molekul DES relina di dalam struktur pelarut metanol. Kelikatan pelarut berkait rapat dengan isi padu teori kelompangan, penyebaran atau pergerakan ion dan perubahan intermolekul [21, 27]. Selain itu, setiap nisbah DES relina dengan kelikatan yang berbeza menunjukkan kepekatan $(\mathrm{mg} / \mathrm{ml}) \alpha-\mathrm{T}$ dan peratus hasil ekstrak (\%) $\alpha$-T yang berbeza-beza.

Merujuk Rajah 7 dan Rajah 8, nisbah 2 DES relina dengan kelikatan $5.7 \pm 0.58 \mathrm{cP}$ merupakan nisbah yang menunjukkan kandungan $\alpha-\mathrm{T}(825.321 \pm 74.27 \mathrm{mg} / \mathrm{L})$ dan peratus hasil ekstrak $(0.1554 \pm 0.0156 \%)$ yang optimum pada masa pengekstrakan 3 jam. Bagi masa pengekstrakan 2 jam, nisbah 3 DES relina dengan kepekatan $8.3 \pm 0.58$ cP menunjukkan kepekatan $\alpha$-T yang paling tinggi. Ini menunjukkan, pemerolehan sebatian $\alpha$-T optimum bagi kedua-dua masa pengekstrakan adalah pada nisbah DES relina yang berbeza. Perbezaan yang ditunjukkan mungkin disebabkan oleh faktor penyebaran molekul $\alpha$-T ke dalam struktur pelarut dan tempoh bagi menghasilkan interaksi yang optimum dengan molekul pelarut DES relina.

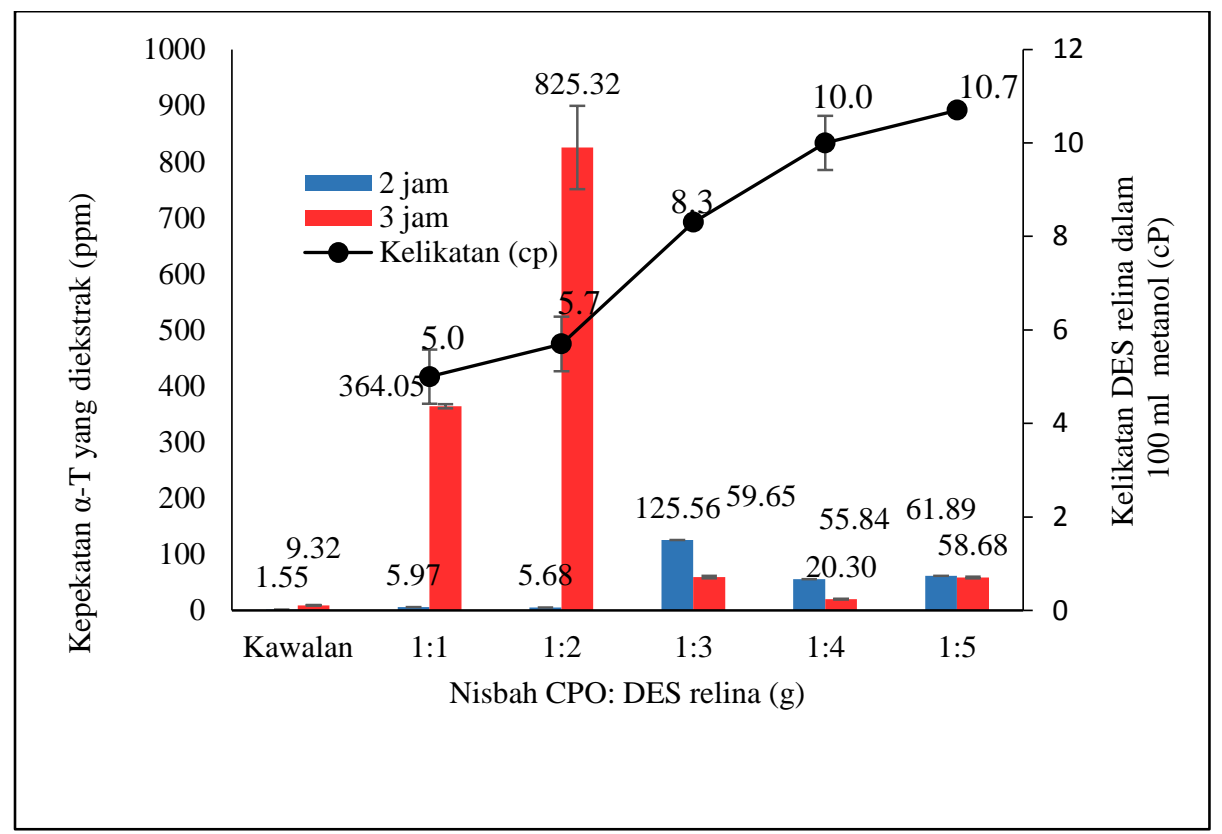

Rajah 7. Kepekatan $\alpha$-T yang diekstrak menggunakan nisbah DES relina dan kelikatan yang berbeza 


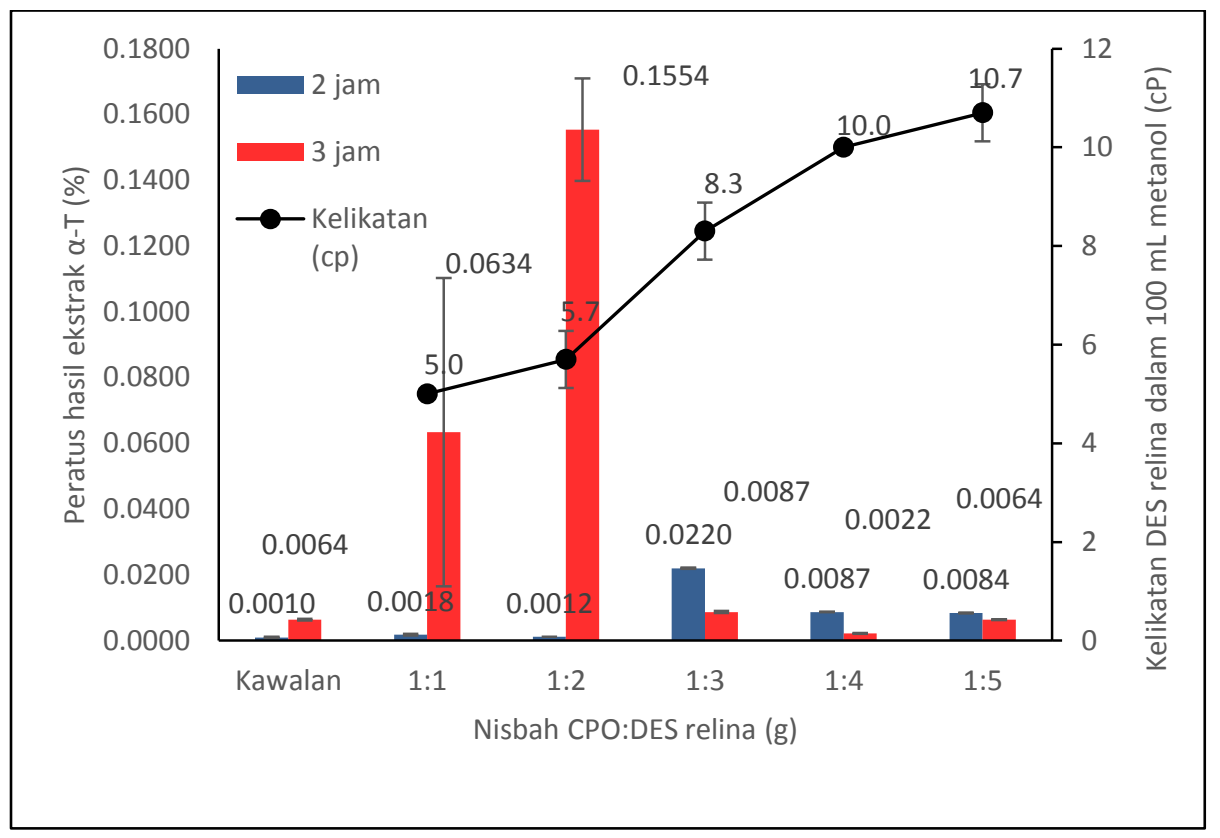

Rajah 8. Peratus hasil ekstrak sebatian $\alpha$-T (\%) menggunakan nisbah DES relina dan kelikatan yang berbeza

Selain itu, Rajah 7 dan Rajah 8 juga menunjukkan pola graf yang sama sekitar nisbah 3 DES relina hingga 5 di mana berlakunya pengurangan kepekatan $\alpha$-T dan hasil ekstrak pada nisbah 3 DES relina kepada 4 dan seterusnya berlaku peningkatan semula pada nisbah 5 DES relina bagi kedua-dua masa pengekstrakan. Di samping itu juga terdapat perbezaan yang ketara pada nisbah 3 hingga 5 DES relina apabila membandingkan kedua-dua masa pengekstrakan. Perbezaan ini dapat dilihat melalui pengurangan kepekatan sebatian $\alpha$-T yang diekstrak dari 2 jam kepada 3 jam masa pengekstrakan.

Pengurangan sebatian $\alpha$-T yang berlaku ini jelas menunjukkan bahawa sebatian ini lebih cenderung untuk terperangkap dalam fasa minyak. Ini adalah disebabkan oleh struktur sebatian $\alpha$-T dengan rantai yang panjang dan tahap kekutuban yang lemah [28]. Pengurangan kepekatan $\alpha$-T yang ditunjukkan juga disebabkan oleh isi padu bebas dalam struktur pelarut yang terhad bagi membolehkan lebih banyak molekul $\alpha$-T tersebar dan berinteraksi dengan pelarut DES relina. Isi padu bebas dalam struktur pelarut DES relina adalah penting kerana saiz molekul $\alpha$-T yang besar memerlukan ruang yang sesuai untuk molekul ini dan molekul pelarut berinteraksi. Selain itu, pada nisbah 3 DES relina kepada 5 menunjukkan masa pengekstrakan 2 jam lebih sesuai berbanding 3 jam. Walaubagaimanapun, masa pengekstrakan 3 jam dengan nisbah 2 DES relina menghasilkan kepekatan sebatian $\alpha$-T yang paling maksimum.

Masa pengekstrakan 3 jam menunjukkan masa ideal bagi menghasilkan interaksi maksimum antara sebatian $\alpha$-T dan molekul pelarut pada nisbah 2 DES relina. Keadaan DES relina pada nisbah 2 membolehkan lebih banyak molekul $\alpha$-T tersebar ke dalam ruang-ruang kosong pelarut dan berinteraksi antara satu sama lain melalui ikatan hidrogen yang ditunjukkan seperti dalam Rajah 9. Ikatan hidrogen yang terhasil ini merupakan analog daripada kajian yang telah dilakukan oleh Xiaolei et al. [25]. Kajian oleh Dai et al. [29] juga menunjukkan bahawa anion $\mathrm{Cl}^{-}$ pada struktur DES relina berpotensi untuk berinteraksi dengan sebatian $\alpha$-T [29] melalui ikatan hidrogen. Walaubagaimanapun, pembentukan ikatan hidrogen yang kuat lebih cenderung berlaku pada kumpulan hidroksil, OH bagi molekul $\alpha$-T kerana kumpulan ini memberikan keasidan ikatan hidrogen yang tinggi [25] untuk berinteraksi dengan pelarut DES relina (kebesan ikatan hidrogen). Pembentukan ikatan hidrogen yang kuat antara molekul $\alpha$-T dan DES relina ini membolehkan pemisahan sebatian $\alpha$-T daripada fasa minyak. 


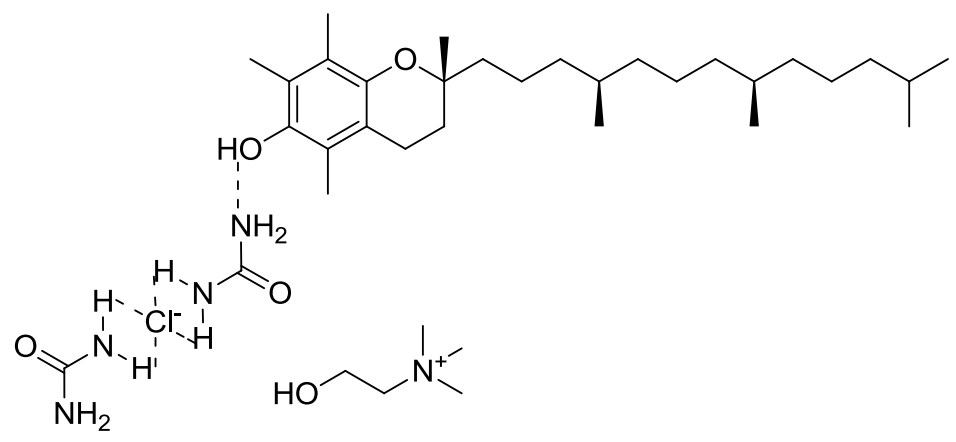

Rajah 9. Analog ikatan hidrogen yang terhasil antara sebatian $\alpha$ - T dan DES relina yang dirujuk daripada kajian Xiaolei et al [25]

Melalui kajian ini, jelas menunjukkan bahawa kelikatan bagi setiap nisbah DES relina dan masa pengekstrakan mempengaruhi kandungan $\alpha$-T yang diekstrak. Walaubagaimanapun, nisbah DES relina yang tinggi menunjukkan kepekatan $\alpha$-T yang rendah. Ini disebabkan oleh pergerakan dan penyebaran molekul $\alpha$-T ke dalam struktur pelarut adalah terbatas. Jadi, interaksi antara kedua-dua molekul ini semakin sukar.

Kepekatan sebatian $\alpha$-T yang diekstrak bagi kesemua sampel dihitung dengan menggunakan kaedah yang telah dilaporkan oleh Nu'man et al. [15] dengan merujuk graf kalibrasi bagi lima siri kepekatan piawai $\alpha$-T yang telah disuntik ke dalam HPLC seperti Rajah 10. Kesemua sampel piawai menunjukkan masa penahanan sekitar $32.503 \pm$ 2.00 min. Berdasarkan kromatogram yang ditunjukkan dalam Rajah 11, masa penahanan sebatian $\alpha$-T menunjukkan bahawa sebatian $\alpha$-T merupakan sebatian yang mempunyai tahap kekutuban yang rendah kerana tempoh penahanan sebatian $\alpha$-T adalah lama. Masa penahanan sebatian terelusi daripada kolum adalah bergantung pada sifat kekutubannya. Sebatian yang mempunyai kekutuban yang tinggi akan mudah dielusi dan masa penahanannya pada fasa pegun adalah lebih singkat.

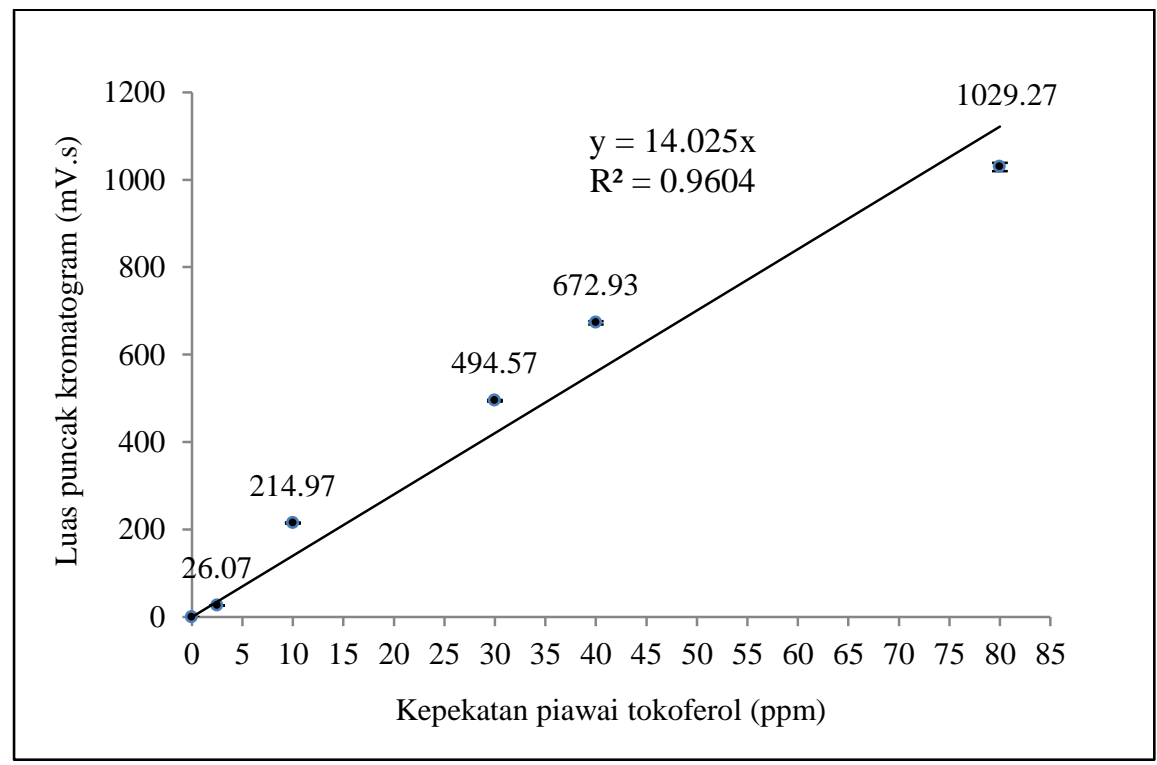

Rajah 10. Graf kalibrasi piawai $\alpha$-T dengan pekali penentuan, $\mathrm{R}^{2}=0.960$ dan faktor gerak balas, $\mathrm{G}=14.02 \mathrm{mV}$.s $\mathrm{mg}^{-1} \mathrm{~L}$ 


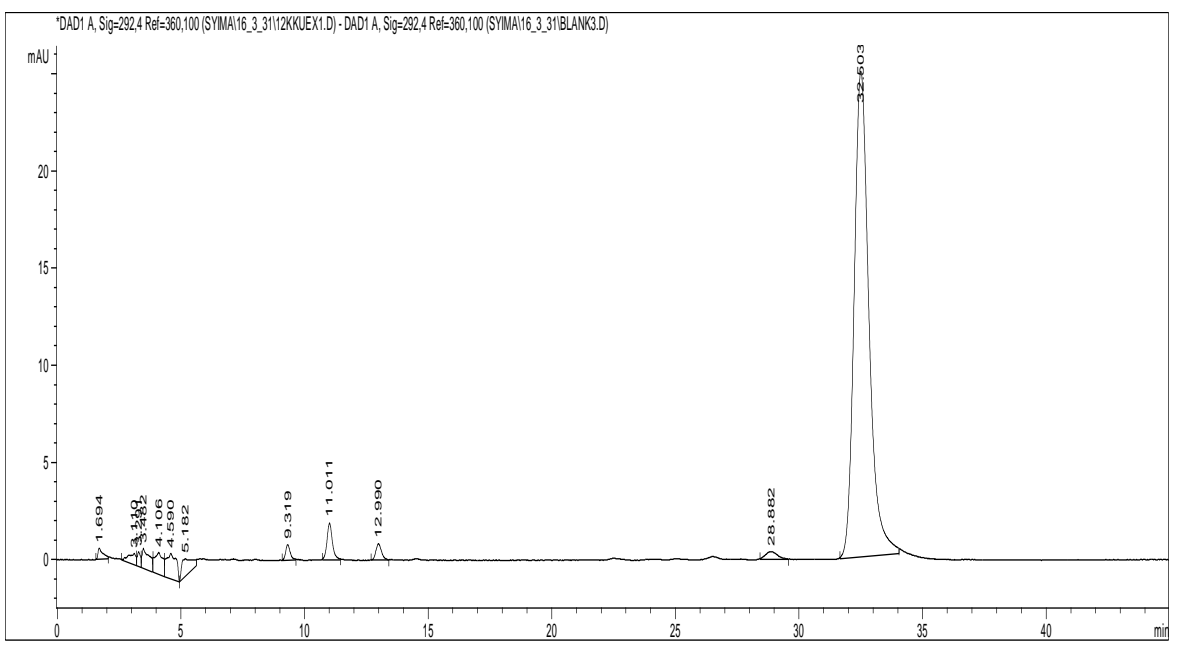

Rajah 11. Kromatogram bagi sampel ekstrak menunjukkan sebatian $\alpha$-T terelusi pada 32.503 minit

\section{Kesimpulan}

DES berpotensi sebagai pelarut pengekstrakan hijau alternatif kerana keupayaannya untuk berinteraksi dengan sebatian dan membentuk sistem dwifasa. Melalui kajian ini, kecekapan DES relina (ChCl-urea) sebagai pelarut pengekstrakan sebatian $\alpha$-T dikaji dengan menggunakan lima siri nisbah CPO: DES relina pada masa pengekstrakan 2 dan 3 jam. Melalui hasil kajian ini, kelikatan DES relina sangat memberi kesan ke atas kecekapan pengekstrakan dan kandungan $\alpha$-T yang diekstrak. Kecekapan pengekstrakan yang ditunjukkan oleh pelarut ini menjadikan DES relina sesuai sebagai pelarut alternatif dalam pengekstrakan sebatian $\alpha$-T. Penggunaan pelarut ini selama 3 jam pengekstrakan pada nisbah CPO:DES relina (1:2) dengan kelikatan DES relina dalam $100 \mathrm{~mL}$ metanol $5.7 \pm 0.58$ cP memberikan hasil kandungan $\alpha$-T yang optimum iaitu sebanyak $825.321 \pm 74.27 \mathrm{mg} / \mathrm{L}$ dengan peratus hasil ekstrak $0.1554 \pm 0.0156 \%$ (w/w). Keupayaan sebatian ini membentuk ikatan hidrogen dengan kumpulan $-\mathrm{OH}$ dan $-\mathrm{NH}_{2}$ pada molekul DES relina membolehkan pemisahan $\alpha$-T daripada fasa tidak berkutub CPO ke fasa berkutub DES berlaku.

\section{Penghargaan}

Ribuan terima kasih ditujukan kepada Universiti Kebangsaan Malaysia dan Kementerian Pendidikan Tinggi, Malaysia atas kemudahan dan geran penyelidikan (FRGS/1/2014/ST01/UKM/02/1, GUP-2017-014) yang disalurkan. Selain itu, ribuan terima kasih diucapkan kepada Pusat Pengajian Sains Kimia dan Teknologi Makanan Fakulti Sains dan Teknologi, UKM dalam menyediakan kemudahan dan alat instrumen bagi memudahkan penyelidikan ini dijalankan.

\section{Rujukan}

1. Mazlan, M., Wan Ngah, W. Z., Mat Top, G. and Then, S. M. (2010). Comparison of the effects of $A$ tocopherol and $\Gamma$-tocotrienol against oxidative stress in two different neuronal cultures. Sains Malaysiana,39:145-56.

2. Top, N. M. H. G. M., Ngan, C. Y. M. M. A., Ma, N. M. H. Y. M. and Wahid, A. N. M. B. (2006). Palm tocols (tocopherols and tocotrienols) as a standard reference materials (MRM 3). Bangi: Malaysian Palm Oil Board, Ministry of Plantation Industries and Commodities, Malaysia.

3. Goh, S. H., Choo, Y. M. and Ong, S. H. (1985). Minor constituents of palm oil. Journal of the American Oil Chemists' Society, 62(2): 237-240.

4. Ng, M. H, Choo, Y. M., Ma, A. N., Chuah, C. H. and Hashim, M. A. (2004). Separation of vitamin E (tocopherol, tocotrienol, and tocomonoenol) in palm oil. Lipids, 39(10): 1031-1035.

5. Ng, M. H., Choo Y. M., Ma A. N., Chuah C. H. and Hashim, M. A. (2004). Isolation of palm tocols using supercritical fluid chromatography. Journal of Chromatographic Science, 42(10):1031-1035. 
Noor Hasyimah et al: STUDY ON VISCOSITY OF RELINE DEEP EUTECTIC SOLVENT ON THE $A$-TOCOPHEROL EXTRACTION FROM CRUDE PALM OIL

6. Choo, Y. M., Ng, M. H., Ma, A. N., Chuah, C. H. and Hashim, M. A. (2005). Application of supercritical fluid chromatography in the quantitative analysis of minor components (carotenes, vitamin e, sterols, and squalene) from palm oil. Lipids,40(4): 429-432.

7. Goossens, B. and Marion, J. (2011). Quantifying vitamin E in vegetable oils with reversed-phase high performance liquid chromatography. Journal of Analytical Chemistry, 2: 44-50.

8. Ruperez, F. J., Martın, D., Herrera, E. and Barbas, C. (2001). Chromatographic Analysis of Alpha-Tocopherol and Related Compounds in Various Matrices. Journal of chromatography A,935(1): 45-69.

9. Sanagi, M. M., See, H. H., Ibrahim, W. A. W., and Naim, A. A. (2005). Determination of carotene, tocopherols and tocotrienols in residue oil from palm pressed fiber using pressurized liquid extraction-normal phase liquid chromatography. Analytica Chimica Acta, 538(1-2): 71-76.

10. Johnson, L. A. and Lusas, E. W. (1983). Comparison of alternative solvents for oils extraction. Journal of the American Oil Chemists' Society, 60(2): 229-242.

11. Nam, M. W., Zhao, J., Lee, M. S., Jeong, J. H. and Lee, J. (2015). Enhanced extraction of bioactive natural products using tailor-made deep eutectic solvents: application to flavonoid extraction from FlosSophorae. Green Chemistry, 17(3):1718-1727.

12. Hayyan, M., Mjalli, F. S., Hashim, M. A. and AlNashef, I. M. (2010). A novel technique for separating glycerine from palm oil-based biodiesel using ionic liquids. Fuel Process Technology, 91: 116-120.

13. Zhang, Q., Vigier, D. O., Royer, K., S. and Jerome, F. (2012). Deep eutectic solvents: Syntheses, properties and applications. Chemical Society Reviews, 41(21): 7108-7146.

14. Abbott, A. P., Cullis, P. M., Gibson, M. J. Harris R. C. and Raven E. (2007). Extraction of gylcerine from biodiesel into eutectic based ionic liquid. Green Chemistry, 9: 868-872.

15. Nu'man, A. H., Ng, M., Choo, Y., Hashim, M. and Jayakumar, N. (2015). Performance of choline-based deep eutectic solvents in the extraction of tocols from crude palm oil. Journal of American Oil Chemical Society, 92(11-12): 1709-1716.

16. Cvjetko, B. M., Ćurko, N., Tomašević, M., Kovačević Ganić, K. and Radojčić Redovniković, I. (2016). Green extraction of grape skin phenolics by using deep eutectic solvents. Food Chemistry, 200: 159-166.

17. Pavia, L. D., Lampman, M. G., Kriz, S. G. and Vyvyan, R. J. (2009). Introduction to spectroscopy. Brooks/Cole Cengage Learning, 4rd Ed. Canada: Lisa Lockwood.

18. Qamar, A. and Leo, B. (2011). Anodic dissolution of refractory metals in choline chloride based binary mixtures. The Electrochemical Society ECS Transactions, 33(30): 57-67.

19. Zaira, M. (2014). Deep eutectic solvents: Properties and biocatalytic applications. Thesis PhD, University (Rheinisch-Westfälische Technische Hochschule Aachen), Germany.

20. Lobo, R. H. (2013). Synthesis of novel colorants for dye-sensitized solar cells and use of greener protocols for heterocyclic synthesis. Thesis PhD. Institute of Chemical Technology, India.

21. D’Agostino, C., Gladden, L. F., Mantle, M. D., Abbott, A. P., Essa, I. A., Al-Murshedi, A. Y. and Harris, R. C. (2015). Molecular and ionic diffusion in aqueous-deep eutectic solvent mixtures: Probing inter-molecular interactions using PFG NMR. Physical Chemistry Chemical Physics, 17(23): 15297-15304.

22. Yue, D., Jia, Y., Yao, Y., Sun, J. and Jing, Y. (2012). Structure and electrochemical behavior of ionic liquid analogue based on choline chloride and urea. Electrochimica Acta, 65: 30-36.

23. Dai, Y., Van S., J., Witkamp, G.-J., Verpoorte, R. and Choi, Y. H. (2013). Ionic liquids and deep eutectic solvents in natural products research: Mixtures of solids as extraction solvents. Journal of Natural Products, 76(11): 2162-2173.

24. Durand, E., Lecomte, J. and Villeneuve, P. (2013). Deep eutectic solvents: Synthesis, application, and focus on lipase-catalyzed reactions. European Journal of Lipid Science and Technology, 115(4): 379-385.

25. Xiaolei, N., Xing, H., Yang, Q., Wang, J., Su, B., Bao, Z. and Ren, Q. (2012). Selective liquid-liquid extraction of natural phenolic compounds using amino acid ionic liquids: a case of $\alpha$-tocopherol and methyl linoleate separation. Industrial \& Engineering Chemistry Research, 51(18): 6480-6488.

26. Haiying, D. (2013). Low transition- temperature mixtures (LTTMs): New generation of designer solvents. Acess from http://ism2.univ-amu.fr/fichiers_pdf/seminaires-stereo/2013-07-15-biblio-2013-04-08-haiyingDU.pdf [23 March 2016].

27. Abbott, A. P., Glen, C. and Stephen, G. (2006). Design of improved deep eutectic solvents using hole theory. European Journal of Chemical Physics and Physical Chemistry, 7(4): 803-806. 
28. Dubbs, M. D. and Gupta, R. B. (1998). Solubility of vitamin E ( $\alpha$-tocopherol) and vitamin K3 (menadione) in ethanol- water mixture. Journal of Chemical \& Engineering Data, 43(4): 590-591.

29. Dai, Y, Van Spronsen, J., Witkamp, G. J., Verpoorte, R. and Choi, Y. H. (2013). Natural deep eutectic solvents as new potential media for green technology. Analytica Chimica Acta, 766: 61-68. 